\title{
Penyuluhan Metode Pembelajaran Matematika Menyenangkan di SD Negeri 01 Karet Kuningan
}

\author{
Evayenny ${ }^{1}$, Nanda Lega Jaya Putra ${ }^{2}$, Syamzah Ayuningrum ${ }^{3}$ \\ 1,2,3 STKIP Kusuma Negara, Jakarta, Indonesia \\ *Corresponding Author: evayenny@stkipkusumanegara.ac.id
}

\begin{abstract}
Info Artikel
Diterima : 03/01/2021

Direvisi: 29/01/2021

Disetujui: 21/02/2021

Abstract. Basic education is undertaken when students are in a period of great potential to be influenced, both positively and negatively. the situation that occurred in SD Negeri Karet Kuningan 01 Pagi, students still have difficulty understanding abstract mathematics material, the lack of teacher knowledge about effective learning methods causes less innovative learning. This phenomenon shows that the teacher's need for a good understanding of mathematics learning methods is an absolute must. The problem that occurred at SD Negeri Karet Kuningan 01 Pagi is the background for the service being carried out. This activity aims to provide knowledge and determine appropriate learning methods for learning mathematics in elementary schools. This PKM is carried out in the form of training, the presentation material in this service activity, namely: (1) Concept of learning methods in accordance with the characteristics of Mathematics subjects (2) Preparation of lesson plans (RPP) with appropriate learning methods (3) Simulation of implementing methods cooperative learning in learning, and (4) assessment of learning using learning methods. Conclusion of this service. Participants are able to carry out learning using the mathematics learning method, the enthusiasm of the participants is high in participating in this training because the material offered is very suitable for their needs as elementary school teachers. Appropriate learning methods can improve the quality of learning, as well as stimulate the ability to work together and a sense of responsibility for elementary students.
\end{abstract}

Keywords: Counseling, Mathematics Learning Methods

\begin{abstract}
Abstrak. Pendidikan dasar dijalani pada saat siswa berada dalam masa yang sangat potensial untuk dipengaruhi, baik itu positif maupun negative. Situasi yang terjadi di SD Negeri Karet Kuningan 01 Pagi, siswa masih kesulitan memahami materi matematika yang abstrak, minimnya pengetahuan guru tentang metode pembelajaran yang efektif menyebabkan pembelajaran yang kurang inovatif. Fenomena tersebut menunjukkan bahwa kebutuhan guru akan pemahaman metode pembelajaran matematika yang baik adalah suatu yang mutlak. Masalah yang terjadi di SD Negeri Karet Kuningan 01 Pagi menjadi latar belakang pengabdian dilaksanakan. Kegiatan ini bertujuan untuk memberikan pengetahuan dan menentukan metode pembelajaran yang sesuai untuk pembelajaran matematika di sekolah dasar. PKM ini dilaksanakan dalam bentuk pelatihan, materi sajian dalam kegiatan pengabdian ini yaitu: (1) Konsep metode-metode pembelajaran sesuai dengan karakteristik mata pelajaran Matematika (2) Pembuatan rencana pelaksanaan pembelajaran (RPP) dengan metode pembelajaran yang sesuai (3) Simulasi pelaksanaan metode pembelajaran kooperatif dalam pembelajaran, serta (4) Penilaian pembelajaran dengan menggunakan metode pembelajaran. Kesimpulan pengabdian ini Peserta mampu melaksanakan pembelajaran dengan menggunakan metode pembelajaran matematika, antusiasme peserta yang tinggi dalam mengikuti pelatihan ini dikarenakan materi yang ditawarkan sangat sesuai dengan kebutuhan mereka sebagai guru SD. Metode pembelajaran yang tepat dapat meningkatkan kualitas pembelajaran, serta merangsaang kemampuan bekerjasama dan rasa tanggung jawab siswa SD.
\end{abstract}

Kata Kunci: Penyuluhan, Metode, Pembelajaran Matematika

How to Cite: Evayenny, E., Putra, N. L. J., \& Ayuningrum, S. (2021). Penyuluhan Metode Pembelajaran Matematika Menyenangkan di SD Negeri 01 Karet Kuningan. Prima Abdika : Jurnal Pengabdian Masyarakat, 1(1), 14-19. https://doi.org/10.37478/abdika.v1i1.931

Copyright (c) 2021 Evayenny, Nanda Lega Jaya Putra, Syamzah Ayuningrum. This work is licensed under a Creative Commons Attribution-ShareAlike 4.0 International License.

\section{Pendahuluan}

Pendidikan dasar boleh dikatakan sebagai jenjang pendidikan yang paling penting bagi siswa. Pendidikan dasar dijalani pada saat siswa berada dalam masa yang sangat potensial untuk dipengaruhi, baik itu positif maupun negatif. Pada masa ini pula, siswa memiliki kemampuan yang optimal untuk menyerap beragam pengetahuan, menginternalisasi nilai-nilai, serta menguasai beberapa keterampilan. Pendidikan dasar di Sekolah Dasar 
(SD) bertujuan secara umum untuk membekali siswa kemampuan membaca, menulis, berhitung serta beberapa keterampilan dasar. Pendidikan merupakan hasil belajar yang berasal dari salah satu bentuk perwujudan kebudayaan manusia yang dinamis dan syarat perkembangan, artinya pekembangan pendidikan akan selalu mengikuti perkembangan zaman (Fayakun \& Joko, 2015).

Menurut Munir Yusuf (2018) dalam Bukunya Pendidikan merupakan bagian yang inhern dengan kehidupan, Pemahaman seperti ini, mungkin terkesan dipaksakan, tetapi jika mencoba merunut alur dan proses kehidupan manusia, maka tidak dapat dipungkiri bahwa pendidikan telah mawarnai jalan panjang kehidupan manusia dari awal hingga akhir. Pendidikan menjadi pengawal sejati dan menjadi kebutuhan asasi manusia.

Pendapat di atas dapat disimpulkan, bahwa pendidikan merupakan suatu proses yang sangat dibutuhkan oleh manusia untuk memeberikan pemahaman mengenai berbagai pengetahuan, pendidikan selalu mengikuti tuntutan perkembangan zaman. Pendidikan didapatkan di sekolah formal ataupun nonformal, salah satu yang unsur dalam pendidikan yaitu pembelajaran, Sunhaji (2014) berpendapat pendidikan adalah suatu usaha untuk membuat siswa belajar, sehingga situasi tersebut merupakan peristiwa belajar adanya interaksi secara langsung antara guru dengan siswa (event of learning) yaitu usaha untuk terjadinya perubahan tingkah laku dari siswa. Upaya melakukan perubahan baik dalam pengetahuan, ataupun tingkah laku membutuhkan berbagai strategi ataupun cara agar siswa lebih mudah menerima dan memahmi materi yang dijelaskan oleh guru, cara tersebut sebagai pola atau pedoman dalam merencanakan pembelajaran di kelas, Trianto (2010).

Metode Pembelajaran penting digunakan oleh guru dalam pembelajaran termasuk pada mata pelajaran matematika. Sebagaimana Dyah Anungrat (2018) mengungakapkan bahwa dalam pembelajaran matematika maka guru perlu mengetahui dan menguasai prinsip-prinsip dan strategi pembelajaran matematika guna tercapainya tujuan dari pembelajaran yang diinginkan, karena pembelajaran seharusnya dikemas secara efektif dan menyenangkan.

Namun situasi yang terjadi di SD demikian masih terdapat kendala dalam pelaksanaanya sehingga guru-guru perlu diberi pelatihan tentang metode-metode pembelajaran. Apalagi bagi siswa SD Negeri Karet Kuningan 01 Pagi, siswa masih kesulitan dalam memahami materi matematika yang abstrak. Minimnya pengetahuan guru tentang metode pembelajaran yang efektif menyebabkan pembelajaran yang dibuat guru kurang inovatif. Fenomena tersebut diatas adalah menunjukkan bahwa kebutuhan guru akan pemahaman metode pembelajaran matematika yang baik adalah suatu yang mutlak.

Berikut macam-macam metode pembelajaran yang dapat diterapkan dalam pembelajaran matematika yang tercantum dalam buku yang dikarang oleh Muhamad Afandi, Evi Chamalah dkk (2013): 1) Metode Karya wisata (Out Door) Outdoor hampir identik dengan pembelajaran karya wisata artinya 
aktivitas belajar siswa dibawa ke luar kelas. Pembelajaran ini harus direncanakan, dalikasanakan, dan dievaluasi secara sistematis dan sistemik; 2) Pengertian Talking Stick Metode pembelajaran talking stick adalah Metode pembelajaran yang dilakukan dengan bantuan tongkat, siapa yang memegang tongkat wajib menjawab pertanyaan dari guru setelah siswa mempelajari materi pokok; 3) Metode Simulasi, metode simulasi adalah suatu cara yang dipergunakan untuk mencapai tujuan yang telah ditetapkan.

Dalam kegiatan belajar mengajar, metode diperlukan oleh guru agar penggunaanya bervariasi sesuai yang ingin dicapai setelah pengajaran berakhir; 4) Metode Discovery Learning, Discovery Learning adalah belajar mencari dan menemukan sendiri. Dalam sistem belajar mengajar ini guru menyajikan bahan pelajaran yang tidak berbentuk final, tetapi anak didik diberi peluang untuk mencari dan menemukan sendiri dengan menggunakan teknik pendekatan pemecahan masalah; 5) Metode Brainstorming, Brainstorming merupakan bentuk dari pengembangan metode diskusi. Metode Brianstroming adalah diskusi membahas suatu masalah oleh sejumlah anggota kelompok, setiap anggota kelompok bebas untuk menyumbangkan ide, saran, pendapat, informasi yang dimiliki, dan gagasan. Masalah yang terjadi di SD Negeri Karet Kuningan 01 Pagi yang menjadi latar belakang pengabdian ini dilaksanakan sehingga kegiatan ini bertujuan untuk memberikan pengetahuan dan menentukan metode pembelajaran yang sesuai untuk pembelajaran matematika di sekolah dasar.

\section{Metode Pelaksanaan}

PKM ini dilaksanakan dalam bentuk pelatihan tiga pertemuan. Peserta pelatihan sejumlah guru SDI Rabbani. Materi sajian dalam kegiatan pengabdian ini yaitu: (1) Konsep metode-metode pembelajaran yang sesuai dengan karakteristik mata pelajaran Matematika beserta contoh pelaksanaan dalam pembelajaran (2) Pembuatan rencana pelaksanaan pembelajaran (RPP) dengan metode pembelajaran yang sesuai (3) Simulasi pelaksanaan model pembelajaran kooperatif dalam pembelajaran, serta (4) Penilaian pembelajaran dengan menggunakan model pembelajaran.

Adapun metode-metode yang digunakan dalam pelatihan ini yakni sebagai berikut: Metode Ceramah, metode ini digunakan untuk menyampaikan teori metode-metode pembelajaran untuk mata pelajaran Matematika. Metode Tanya Jawab, metode ini digunakan untuk mengidentifikasi sejauh mana pemahaman peserta terhadap materi yang disajikan. Metode Pemberian Tugas, tugas yang diberikan yaitu memilih materi pembelajaran dan menyusun RPP pembelajaran di SD. Metode Diskusi, metode ini digunakan dalam mendiskusikan materi pembelajaran, rancangan RPP, serta tugas-tugas yang telah disusun peserta. Metode yang terakhir adalah Metode Simulasi, metode ini digunakan untuk mensimulasikan RPP yang telah disusun.

\section{Hasil dan Pembahasan}

Pada pertemuan pertama, materi pelatihan tentang berbagai metode pembelajaran Matematika yang dapat di aplikasikan di dalam pembelajaran 
dan diberikan contoh rencana pembelajarannnya. Peserta pelatihan memahami konsep metode pembelajaran yang telah disajikan oleh pemateri. Metode-metode tersebut adalah demonstrasi, eksperimen, diskusi kelompok, dan permainan

Peserta sudah mampu mengembangkan rencana pelaksanaan pembeljaran. Pada pertemuan ini, peserta memaparkan rencana pembelajaran, dan didiskusikan apakah rencana pembelajaran yang dukembangkan sudah sesuai dengan metode yang dipilih

Peserta mampu melaksanakan pembelajaran dengan menggunakan metode pembelajaran Matematika. Antusiasme peserta yang tinggi dalam mengikuti pelatihan ini dikarenakan materi yang ditawarkan sangat sesuai dengan kebutuhan mereka sebagai guru SD. Metode-metode pembelajaran dianggap cukup efektif bagi peserta dalam memecahkan masalah-masalah pembelajaran pada umumnya yang cenderung menjadikan siswa SD pasif. Metode pembelajaranyang tepat dapat meningkatkan kualitas pembelajaran, karena mampu meningkatkan kemauan dan partisipasi siswa dalam pembelajaran, memunculkan diskusi yang mengaktifkan kemampuan berfikir siswa, serta merangsaang kemampuan bekerjasama dan rasa tanggung jawab dari siswa SD.

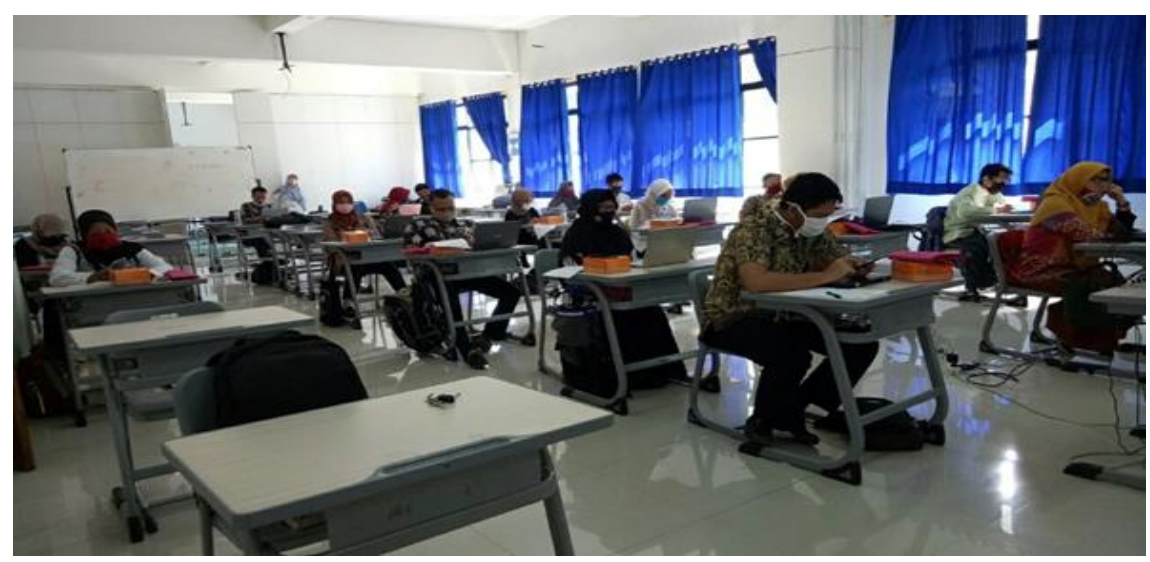

Gambar 1. Peserta Menyimak Penyampaian Materi

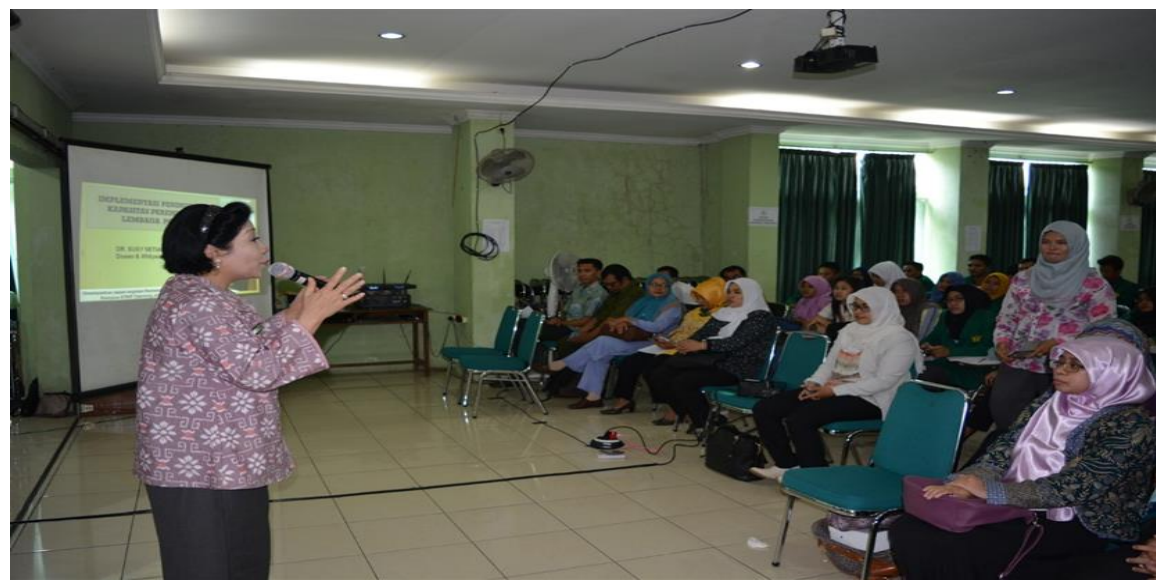

Gambar 2. Salah Satu Peserta Memberikan Ice Breaking 


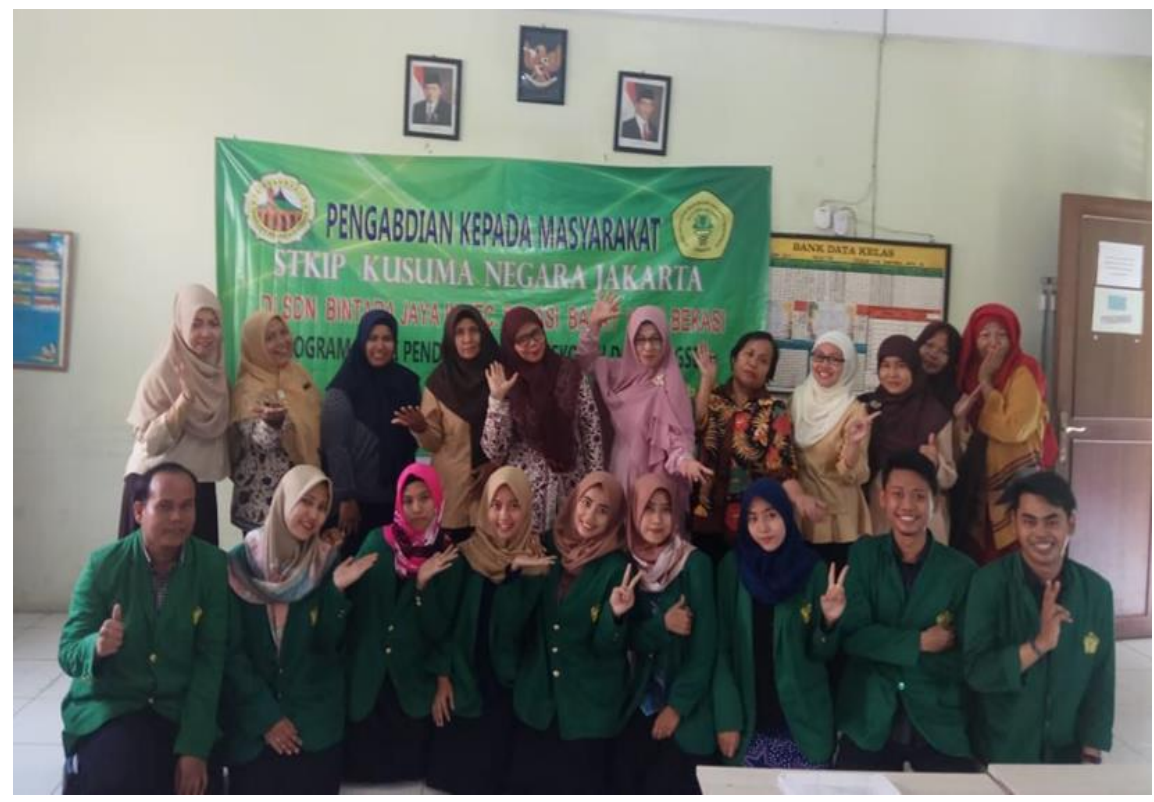

Gambar 3. Foto Bersama Tim PKM

\section{Simpulan dan Tindak Lanjut}

Kesimpulan yang dapat ditarik dari pelaksanaan program Pengabdian Kepada Masyarakat (PKM) ini adalah sebagai berikut: Kegiatan ini dapat meningkatkan keterampilan guru SDN dalam merancang serta melaksanakan pembelajaran yang lebih atraktif dan merangsang keaktifan siswa SD. Program ini juga meningkatkan motivasi peserta untuk meningkatkan wawasan dan pengetahuan terkait metode pembelajaran secara umum, serta memacu peserta untuk meningkatkan profesionalisme mereka dalam pelaksanaan pembelajaran. Metode pembelajaran Matematika dapat menjadi alternatif solusi bagi guru SDN 01 Karet Kuningan untuk meningkatkan kualitas pembelajaran serta mencapai tujuan dari pembelajaran.

Peserta pelatihan diharapkan dapat menerapkan metode pembelajaran yang sesuai di kelas masing-masing, serta dapat melatih guru-guru sejawatnya. Pihak-pihak pengelola pendidikan seperti Kepala UPTD Pendidikan, Pengawas SD, serta Kepala SD agar memberikan kesempatan yang lebih banyak kepada guru-guru SD untuk meningkatkan kualitas pembelajaran.

\section{Daftar Pustaka}

Afandi, M., Chamalah, E., Wardani, O. P., \& Gunarto, H. (2013). Model dan metode pembelajaran. Semarang: UNISSULA.

Fayakun, M., \& Purnomo, J. (2015). Efektivitas Pembelajaran Fisika Menggunakan Model Kontekstual (CTL) Dengan Metode Predict, Observe, Explain Terhadap Kemampuan Berfikir Tingkat Tinggi. Jurnal Pendidikan Fisika Indonesia, 11(1), 26- 
37.https://journal.unnes.ac.id/nju/index.php/JPFI/article/view/4003 /3703

Herzamzam, D. A. (2018). Peningkatkan Minat Belajar Matematika Melalui Pendekatan Matematika Realistik (PMR) Pada Siswa Sekolah Dasar. Visipena, 9(1), 67-80. https: / / ejournal.bbg.ac.id/visipena/article/view/430/392

Sunhaji, S. (2014). KONSEP MANAJEMEN KELAS DAN IMPLIKASINYA DALAM PEMBELAJARAN. Jurnal Kependidikan, 2(2), 30-46. https: / /doi.org/https:/ / doi.org/10.24090/jk.v2i2.551

Trianto. (2010). Model Pembelajaran Terpadu, Konsep, Strategi dan Implementasinya dalam KTSP. Jakarta: Bumi Aksara.

Munir, Y. (2018) Pengantar Imu Pendidikan. Palopo: Lembaga Penerbit Kampus IAIN Palopo. 